\title{
The Circulatory Effects of Epinephrine Infusion in the Anesthetized Piglet
}

\author{
KEITH BARRINGTON AND WINSTON CHAN \\ Department of Pediatrics and Centre for Research In Maternal, Fetal, and Newborn Health. \\ University of Alberta. Edmonton, Alberta. Canada
}

\begin{abstract}
There are few published data regarding the circulatory effects of systemic epinephrine infusions in newborn subjects. We therefore instrumented six piglets aged 5 to $10 \mathrm{~d}$ while they were under pentobarbitone anesthesia for determination of cardiac output, left anterior descending coronary artery flow, systemic and pulmonary pressures, and mixed venous, arterial and coronary sinus gases. Systemic, coronary, and pulmonary vascular resistances, coronary oxygen consumption, and myocardial oxygen extraction ratio were calculated. Epinephrine was infused at doses from 0.2 to $3.2 \mu \mathrm{g} / \mathrm{kg} / \mathrm{min}$ doubling at $15-$ min intervals, and measurements were taken after stability had been obtained. Cardiac output increased at the lowest dose investigated, i.e. $0.2 \mu \mathrm{g} / \mathrm{kg} / \mathrm{min}$, and progressively increased as the dose was advanced up to $1.6 \mu \mathrm{g} / \mathrm{kg} / \mathrm{min}$, decreasing significantly at $3.2 \mu \mathrm{g} / \mathrm{kg} / \mathrm{min}$. Blood pressure increased progressively, being significantly above baseline at $0.8,1.6$, and $3.2 \mu \mathrm{g} / \mathrm{kg} / \mathrm{min}$ and having increased by approximately $81 \%$ at the highest dose investigated. Pulmonary arterial pressures were also increased at 1.6 and $3.2 \mu \mathrm{g} / \mathrm{kg} / \mathrm{min}$, but only by $35 \%$ at the highest dose of 3.2 $\mu \mathrm{g} / \mathrm{kg} / \mathrm{min}$. Systemic and pulmonary vascular resistances both decreased at the three lower doses investigated and then began to increase progressively; however, the systemic vascular resistance increased to a significantly greater degree than pulmonary vascular resistance. Coronary oxygen consumption increased progressively as the epinephrine dose was increased; however, coronary blood flow and coronary oxygen delivery increased more than oxygen consumption, leading to a progressive reduction in myocardial oxygen extraction ratio and a progressive increase in coronary sinus oxygen content. Whole-body oxygen consumption was increased, but to a lesser extent than systemic oxygen transport. We conclude that, at low doses, epinephrine is a potent inotrope and a systemic and pulmonary vasodilator in the newborn piglet. With progressive increases in the dose, systemic vasoconstriction is significantly greater than pulmonary. Increasing cardiac oxygen demands are oversupplied by increases in coronary blood flow. (Pediatr Res 33: 190-194, 1993)
\end{abstract}

\section{Abbreviations}

PVR, pulmonary vascular resistance SVR, systemic vascular resistance

There is little published data regarding the circulatory effects of epinephrine infusions in newborn subjects. Epinephrine in-

Received April 29, 1992: accepted September 29, 1992.

Correspondence: Dr. K. Barrington, 3A3 Walter MacKenzie Centre, University of Alberta, 8440-112 Street, Edmonton, AB, T6G 2B7 Canada. fusions are occasionally used as a back-up inotropic therapy for sick newborn infants (1), particularly those with persistent pulmonary hypertension of the newborn. In such infants, pulmonary vascular resistance is elevated and cardiac output is low (2). A drug that has selective pulmonary vasodilating or selective systemic pressor and positive inotropic properties would therefore be of great value. One previous study of the effects of highdose epinephrine infusions $(3.5,7$, and $15 \mu \mathrm{g} / \mathrm{kg} / \mathrm{min})(3)$ in newborn piglets with group B streptococcus-induced pulmonary hypertension suggested a selective systemic pressor effect. To obtain additional information regarding the effects of this mode of therapy, the following study was performed to determine the effects of epinephrine infusions at lower, clinically applicable doses in healthy, acutely instrumented piglets on cardiac index, SVR, and PVR.

Epinephrine can significantly increase myocardial $\mathrm{O}_{2}$ consumption (4) and coronary vascular resistance (5). We therefore felt it important to determine the effects of systemic epinephrine infusion on the myocardial $\mathrm{O}_{2}$ supply and demand relationship. To our knowledge, this has not been attempted previously.

We hypothesized that epinephrine would decrease PVR and increase cardiac output in the newborn piglet. We further hypothesized that myocardial $\mathrm{O}_{2}$ demand would increase more than $\mathrm{O}_{2}$ supply, leading to a decrease in coronary sinus $\mathrm{O}_{2}$ content.

\section{MATERIALS AND METHODS}

Seven newborn piglets were obtained and anesthesia was induced with $5 \%$ inhaled halothane and then decreased to $2 \%$. A cutdown was performed in one groin for the insertion of a femoral arterial line and a double lumen venous catheter. After insertion of this catheter, $20 \mathrm{mg} / \mathrm{kg}$ pentobarbitone was administered and the halothane was discontinued. This took a maximum of $8 \mathrm{~min}$. Subsequent maintenance of anesthesia was by supplemental $5-\mathrm{mg} / \mathrm{kg}$ doses of pentobarbitone. A tracheostomy was performed, and assisted ventilation was commenced. Pancuronium was administered to maintain muscle relaxation. Through the right external jugular vein, a catheter was advanced into the right atrium for the measurement of right atrial pressure. At this point, the animal was turned onto its right side and a left thoracotomy in the fourth intercostal space was performed. A 6 or 8-mm Transonic transit time ultrasound flow probe (Transonics Corporation, Ithaca, NY) was placed around the main pulmonary artery to measure cardiac output, and a 24-gauge catheter was introduced into the root of the pulmonary artery for the measurement of pulmonary artery pressures. Through the hemiazygos vein, a catheter was advanced to lie in the coronary sinus. The hemiazygos vein was ligated around the catheter. In five animals, a 1-mm Transonics flow probe was placed around the left anterior descending coronary artery. After these procedures were performed, blood gases were taken and $15 \mathrm{~min}$ of recording performed to ensure that the animal was stable. At this time, further progress of this experiment was only allowed if the $\mathrm{PaO}_{2}$ 
was greater than $13.3 \mathrm{kPa}(100 \mathrm{~mm} \mathrm{Hg})$, the arterial $\mathrm{CO}_{2}$ tension was between 4.9 and $5.7 \mathrm{kPa}(37$ and $43 \mathrm{~mm} \mathrm{Hg}$ ), and the $\mathrm{pH}$ was between 7.35 and 7.45. The assisted ventilation and inspired $\mathrm{O}_{2}$ concentration were adjusted to achieve blood gas values within this range. During this period, the chest was open and the animals were infused with normal saline at a rate of $30 \mathrm{~mL} / \mathrm{kg}$ / $\mathrm{h}$ to compensate for the high insensible losses. We ensured that the animals were continuing to produce urine and had a stable right atrial pressure, heart rate, and cardiac output.

After this baseline monitoring period, epinephrine was administered at a rate of $0.2 \mu \mathrm{g} / \mathrm{kg} / \mathrm{min}$. This was diluted in normal saline, and the total i.v. rate was kept constant throughout the experiment. Epinephrine infusion was continued for at least 15 min or until no further change could be seen in any of the continuously monitored variables (which in fact always took less than $15 \mathrm{~min}$ ). At the end of this 15 -min period, an arterial blood gas sample was taken; blood samples were also obtained from the pulmonary artery and from the coronary sinus catheter. The blood gases were analyzed with an IL 1306 blood gas analyzer (Instrumentation Laboratory, Fisher Scientific, Lexington, MA), and $\mathrm{Hb}$ was measured by a hemoglobinometer (Coulter Electronics, Hialeah, FL). $\mathrm{O}_{2}$ contents were calculated. From these variables, we were able to calculate the following: PVR index (the quotient of mean pulmonary artery pressure and cardiac index), SVR index (the quotient of mean systemic arterial pressure minus right atrial pressure and cardiac index), and mean coronary vascular resistance. We calculated the following $\mathrm{O}_{2}$ transport variables: systemic $\mathrm{O}_{2}$ transport, $\mathrm{O}_{2}$ consumption (Fick principle), coronary $\mathrm{O}_{2}$ delivery (coronary blood flow multiplied by arterial $\mathrm{O}_{2}$ content), coronary $\mathrm{O}_{2}$ consumption (the product of coronary blood flow and the difference between arterial and coronary sinus $\mathrm{O}_{2}$ content), and myocardial $\mathrm{O}_{2}$ extraction ratio. Subsequently, the epinephrine dose was doubled to $0.4,0.8,1.6$, and $3.2 \mu \mathrm{g} / \mathrm{kg} / \mathrm{min}$, and at each dose increment the same variables were measured after $15 \mathrm{~min}$. At the conclusion of the 15 min of infusion of epinephrine at $3.2 \mu \mathrm{g} / \mathrm{kg} / \mathrm{min}$, the infusion was discontinued and all variables were recorded to determine whether they would return to preepinephrine values. Results are presented as mean and SD. Statistical analysis was by randomized block-design analysis of variance with post hoc testing by Fisher's-protected least significant difference. A significance level of $<0.05$ was considered acceptable.

\section{RESULTS}

Cardiac index was significantly increased $(p<0.05)$ at the lowest dose of epinephrine investigated and progressively increased up to a dose of $1.6 \mu \mathrm{g} / \mathrm{kg} / \mathrm{min}(p<0.001$ compared with baseline). Both heart rate and stroke volume index were increased (Table 1). At $3.2 \mu \mathrm{g} / \mathrm{kg} / \mathrm{min}$, there was a significant reduction in cardiac output compared with $1.6 \mu \mathrm{g} / \mathrm{kg} / \mathrm{min}(p<0.05$, Fig. 1$)$. This was due to a reduction in stroke volume index. Mean arterial blood pressure was unchanged until a dose of $0.8 \mu \mathrm{g} / \mathrm{kg} /$ min was reached and was significantly elevated at the three higher doses $(p<0.05$, Fig. 2). SVR index and PVR index both decreased at $0.2,0.4$, and $0.8 \mu \mathrm{g} / \mathrm{kg} / \mathrm{min}(p<0.05)$. At $1.6 \mu \mathrm{g} /$ $\mathrm{kg} / \mathrm{min}$, there was a significant increase in SVR index to a level similar to the baseline $(p<0.05$ compared with $0.8 \mu \mathrm{g} / \mathrm{kg} / \mathrm{min}$, $p=$ NS compared with baseline). At $3.2 \mu \mathrm{g} / \mathrm{kg} / \mathrm{min}$, there was an increase in the SVR index to a level significantly above baseline $(p<0.05$, Table 1). PVR index increased at 1.6 and 3.2 $\mu \mathrm{g} / \mathrm{kg} / \mathrm{min}$ but remained somewhat less than baseline. As a result, the SVR index:PVR index ratio was significantly increased at 1.6 and $3.2 \mu \mathrm{g} / \mathrm{kg} / \mathrm{min}(p<0.05$ for $1.6, p<0.01$ for 3.2 ; Fig. 3 ). Coronary blood flow increased as the dose was increased (all doses $p<0.01$ compared with baseline, Fig. 4). Mean coronary vascular resistance was decreased significantly below baseline at a dose of $0.2 \mu \mathrm{g} / \mathrm{kg} / \mathrm{min}$ and decreased further at $0.4 \mu \mathrm{g} / \mathrm{kg} / \mathrm{min}$, remaining significantly below baseline and below the $0.2 \mu \mathrm{g} / \mathrm{kg} /$ min value as the dose increased further (Fig. 5). Coronary $\mathrm{O}_{2}$ consumption increased progressively with increasing epinephrine doses, being significantly greater than baseline at $0.4 \mu \mathrm{g} / \mathrm{kg} / \mathrm{min}$ and all higher doses $\left(p<0.01\right.$, Fig. 6). Myocardial $\mathrm{O}_{2}$ consumption was oversupplied by the increasing coronary $\mathrm{O}_{2}$ delivery, with a consequent progressive increase in coronary sinus $\mathrm{O}_{2}$ saturation (Table 1) and a reduction in the myocardial $\mathrm{O}_{2}$ extraction ratio (Fig. 7). Whole-body $\mathrm{O}_{2}$ consumption increased significantly at $0.4 \mu \mathrm{g} / \mathrm{kg} / \mathrm{min}$ and above (Fig. 8). However, the increase in $\mathrm{O}_{2}$ delivery was far greater than the increase in consumption and, therefore, mixed venous $\mathrm{O}_{2}$ content increased as the dose of epinephrine increased (Table 1).

\section{DISCUSSION}

The ideal drug for treatment of persistent pulmonary hypertension of the newborn would be a specific pulmonary vasodilator with positive inotropic properties (2). From the current investigation, it appears that this hemodynamic profile can be provided by epinephrine infusions of $0.8,1.6$, and $3.2 \mu \mathrm{g} / \mathrm{kg} /$ min. Although epinephrine has been in clinical use as an inotrope, chronotrope, and peripheral vasoconstrictor as a bolus medication given during resuscitation (6), the effects of epinephrine infusions have received little attention. The only publication documenting use of epinephrine infusions in young children reports three infants with severe congestive heart failure from left to right shunts (7). The therapeutic use of epinephrine infusions has also been reported in the postoperative period after cardiac surgery in adults who usually receive low doses, i.e. approximately $0.06 \mu \mathrm{g} / \mathrm{kg} / \mathrm{min}$ epinephrine (8-10).

The circulatory effects of catecholamine infusions require further definition in the neonatal population, as there is little information regarding the ontogeny of catecholamine receptors in the systemic and pulmonary circulation of neonatal mammals. The effects of catecholamine infusions and the dose-response relationships cannot therefore be predicted, but require empirical investigation. We have demonstrated that epinephrine has differential effects on the systemic and pulmonary circulation in the newborn piglet. In part, this may be because of a differential development of $\alpha$-receptors. The $\alpha_{2}$-receptor stimulant, phenylephrine, has previously been demonstrated to cause systemic but not pulmonary vasoconstriction in newborn piglets with group B streptococcal pulmonary hypertension (11). That investigation found a significant decrease in cardiac output associated with the increase in SVR and therefore demonstrated that: 1) the

Table 1. Cardiac output, vascular resistance, coronary, and systemic $\mathrm{O}_{2}$ transport variables with increasing epinephrine dose*

\begin{tabular}{cccccccc}
\hline $\begin{array}{c}\text { Dose } \\
(\mu \mathrm{g} / \mathrm{kg} / \mathrm{min})\end{array}$ & $\begin{array}{c}\text { SVRI } \\
(\mathrm{kPa} / \mathrm{mL} / \mathrm{kg} / \mathrm{min})\end{array}$ & $\begin{array}{c}\text { PVRI } \\
(\mathrm{kPa} / \mathrm{mL} / \mathrm{kg} / \mathrm{min})\end{array}$ & $\begin{array}{c}\text { Coronary } \mathrm{O}_{2} \\
\text { delivery } \\
(\mathrm{mL} / \mathrm{min})\end{array}$ & $\begin{array}{c}\text { Coronary sinus } \\
\mathrm{O}_{2} \text { content } \\
(\mathrm{mL} / 100 \mathrm{~mL})\end{array}$ & $\begin{array}{c}\text { Pulse } \\
(/ \mathrm{min})\end{array}$ & $\begin{array}{c}\text { Stroke volume } \\
\text { index } \\
(\mathrm{mL} / \mathrm{kg})\end{array}$ & $\begin{array}{c}\text { Mixed venous } \\
\mathrm{O}_{2} \text { content } \\
(\mathrm{mL} / 100 \mathrm{~mL})\end{array}$ \\
\hline 0 & $0.079(0.017)$ & $0.025(0.006)$ & $135(34)$ & $6.8(1.0)$ & $212(32)$ & $0.67(0.24)$ & $8.2(1.3)$ \\
0.2 & $0.068(0.016)$ & $0.021(0.005)$ & $177(46)$ & $8.0(1.5)$ & $233(32)$ & $0.71(0.20)$ & $8.8(1.9)$ \\
0.4 & $0.064(0.014)$ & $0.020(0.005)$ & $209(31)$ & $7.9(0.9)$ & $253(27)$ & $0.71(0.21)$ & $8.9(1.7)$ \\
0.8 & $0.065(0.013)$ & $0.019(0.006)$ & $239(79)$ & $8.0(1.5)$ & $262(17)$ & $0.75(0.21)$ & $8.7(1.6)$ \\
1.6 & $0.079(0.024)$ & $0.021(0.010)$ & $328(56)$ & $9.4(1.4)$ & $280(32)$ & $0.70(0.14)$ & $9.8(2.1)$ \\
3.2 & $0.12(0.055)$ & $0.029(0.018)$ & $368(46)$ & $10.3(1.2)$ & $286(35)$ & $0.45(0.32)$ & $10.7(1.7)$ \\
\hline
\end{tabular}

${ }^{*}$ Results are given as mean (SD). SVRI, systemic vascular resistance index; PVRI, pulmonary vascular resistance index. 


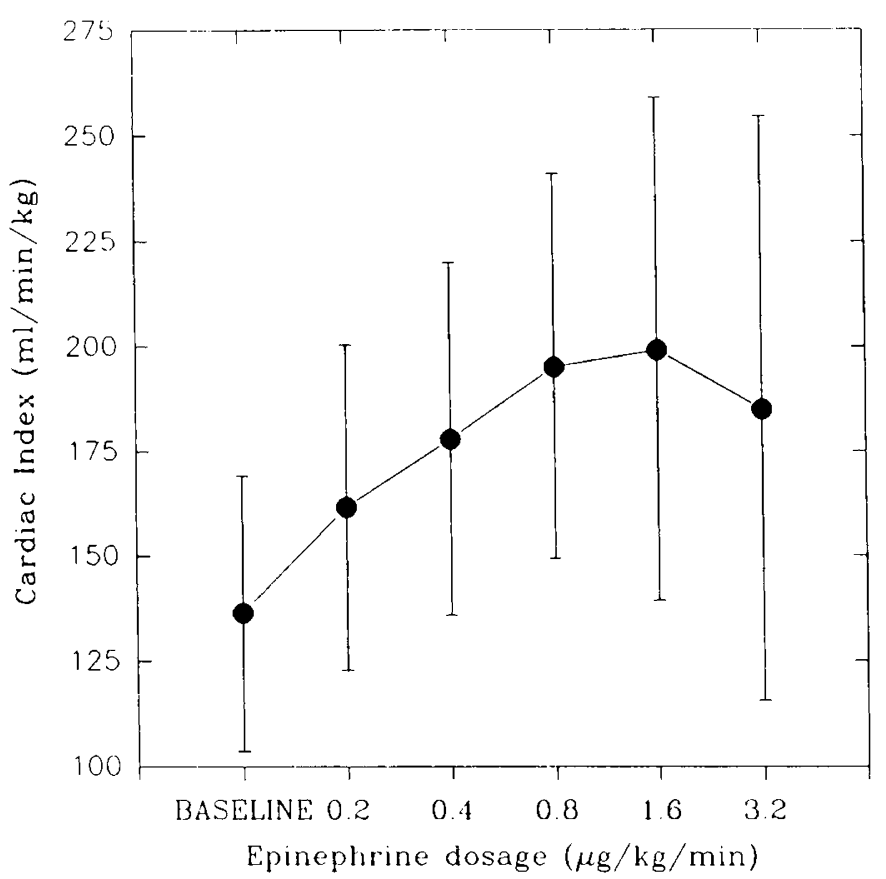

Fig. 1. Cardiac index response to increasing epinephrine dose.

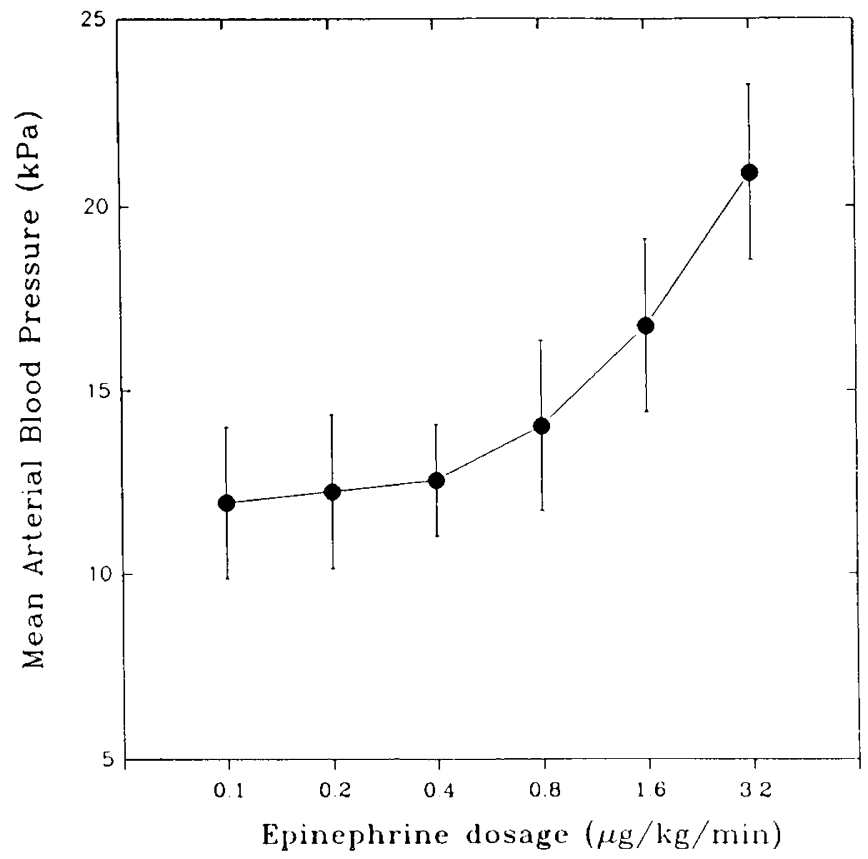

Fig. 2. Mean arterial blood pressure response to increasing epinephrine dose.

neonatal heart is very intolerant of increases in afterload and tends to respond to vasoconstriction with a decrease in cardiac output rather than an increase in blood pressure (12), and 2) the $\alpha_{2}$-receptor-mediated effects are less evident in the neonatal mammalian pulmonary circulation. This differential intensity of $\alpha$-effects may explain the results that we have presented in this article. The balance between $\alpha$ - and $\beta$-stimulation produced by epinephrine appears to be because, at the low doses that we have investigated, $\beta$-effects predominate. As the dose increases, $\alpha$ effects gradually become more prominent and begin to cause significant vasoconstriction, which is mostly confined to the systemic circulation. Thus, at low doses, vascular resistance falls and cardiac output increases because of increases in both heart rate and stroke volume. At moderate doses, the positive inotropic effects of epinephrine override the increase in SVR that appears

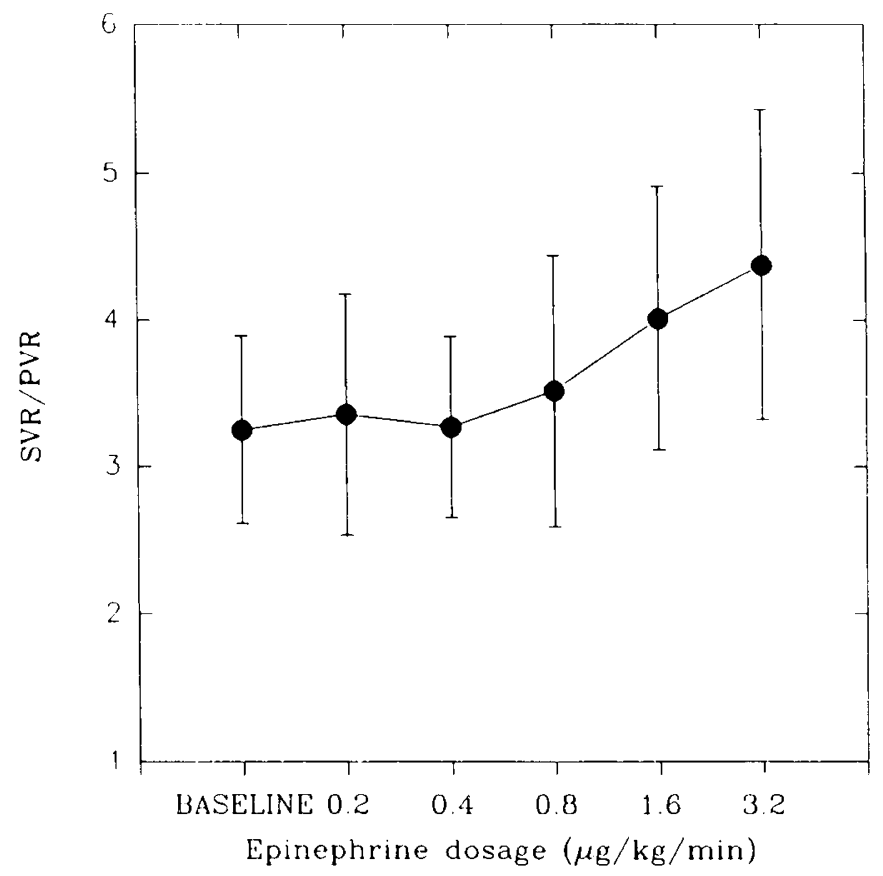

Fig. 3. SVR:PVR ratio response to increasing epinephrine dose.

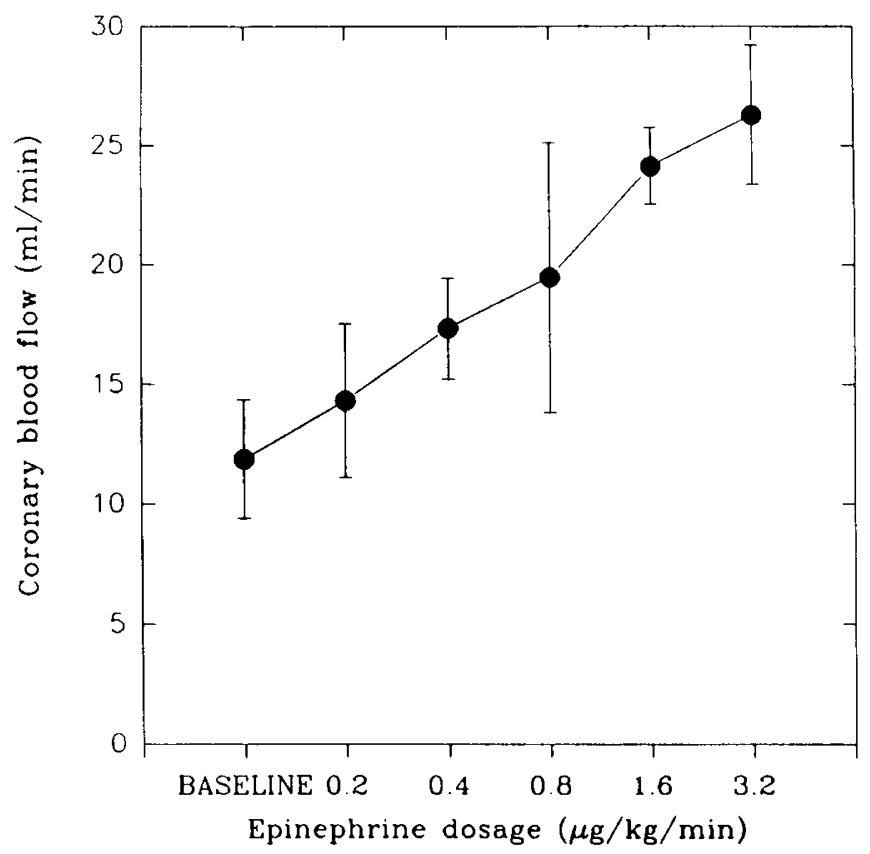

Fig. 4. Coronary blood flow response to increasing epinephrine dose.

and cardiac output increases further. However, at the highest dose that we investigated $(3.2 \mu \mathrm{g} / \mathrm{kg} / \mathrm{min})$, the intolerance of the neonatal myocardium to increased afterload is demonstrated as cardiac output decreases slightly.

The epinephrine doses were given in the same order to each animal, and we did not attempt to randomize the order of the medications. This was done to mimic the usual or clinical approach to initiating inotrope therapy when the medication is usually started in a low dose and gradually increased in a stepwise fashion to achieve the desired clinical benefit. It is possible that there was some cumulative change in physiologic response during the study, which this protocol would not be able to demonstrate.

The highest dose that we investigated was similar to the lowest dose investigated by Meadow et al. (3). We can thus compare the results of our high-dose infusions with the lowest dose used in their study. Our anesthetic regimens were similar; however, 


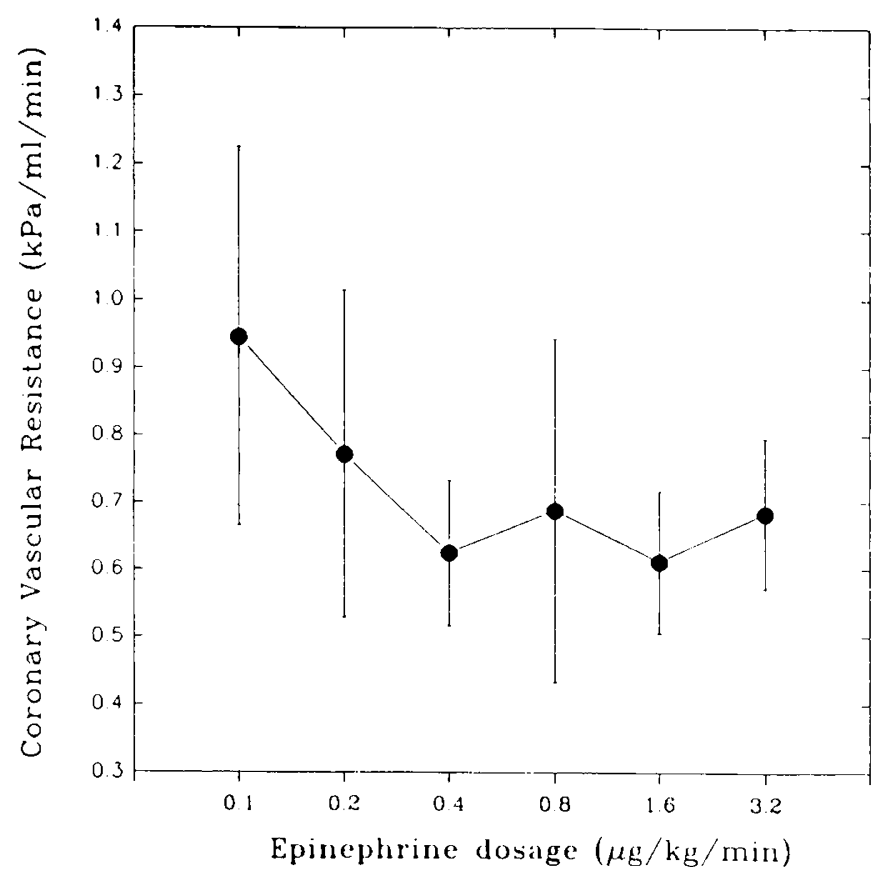

Fig. 5. Mean coronary vascular resistance response to increasing epinephrine dose.

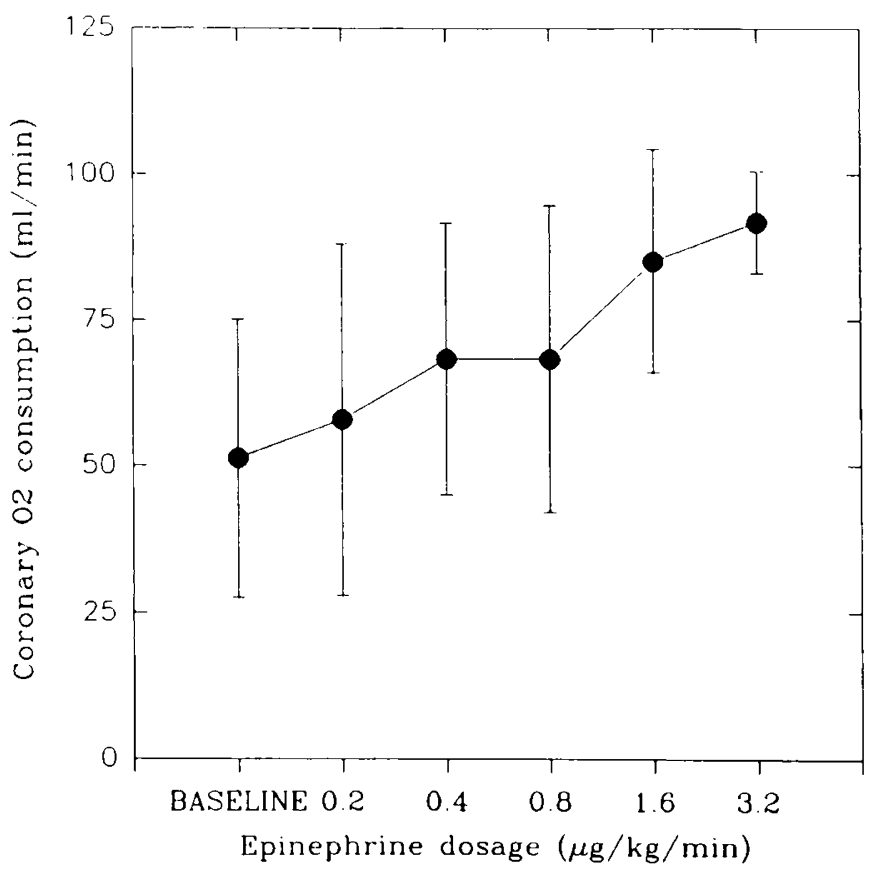
dose

Fig. 6. Coronary $\mathrm{O}_{2}$ consumption response to increasing epinephrine

they only gave epinephrine to piglets who had received group B streptococcal infusions. Their piglets therefore had an increase in cardiac index of only $4.6 \mathrm{~mL} / \mathrm{kg} / \mathrm{min}$ at a dose of $3.5 \mu \mathrm{g} / \mathrm{kg} /$ min of epinephrine compared with an increase of $49 \mathrm{~mL} / \mathrm{kg} /$ $\min$ at $3.2 \mu \mathrm{g} / \mathrm{kg} / \mathrm{min}$ in the current study. As the dose increased, Meadow et al. found a reduction in the cardiac index such that at $15 \mu \mathrm{g} / \mathrm{kg} / \mathrm{min}$, there was a decrease in cardiac index of 13.4 $\mathrm{mL} / \mathrm{kg} / \mathrm{min}$. They demonstrated at the $3.5-\mu \mathrm{g} / \mathrm{kg} / \mathrm{min}$ dose an increase in SVR index of $0.019 \mathrm{kPa} / \mathrm{mL} / \mathrm{min} / \mathrm{kg}(0.144 \mathrm{~mm} \mathrm{Hg} /$ $\mathrm{mL} / \mathrm{min} / \mathrm{kg}$ ) and a decrease in PVR index of $0.0088 \mathrm{kPa} / \mathrm{mL} /$ $\mathrm{min} / \mathrm{kg}(0.066 \mathrm{~mm} \mathrm{Hg} / \mathrm{mL} / \mathrm{min} / \mathrm{kg})$ from the level obtained after group B streptococcal infusions, which had elevated both the SVR index and PVR index to well above baseline. We demonstrated, in contrast, an elevation of PVR index at the

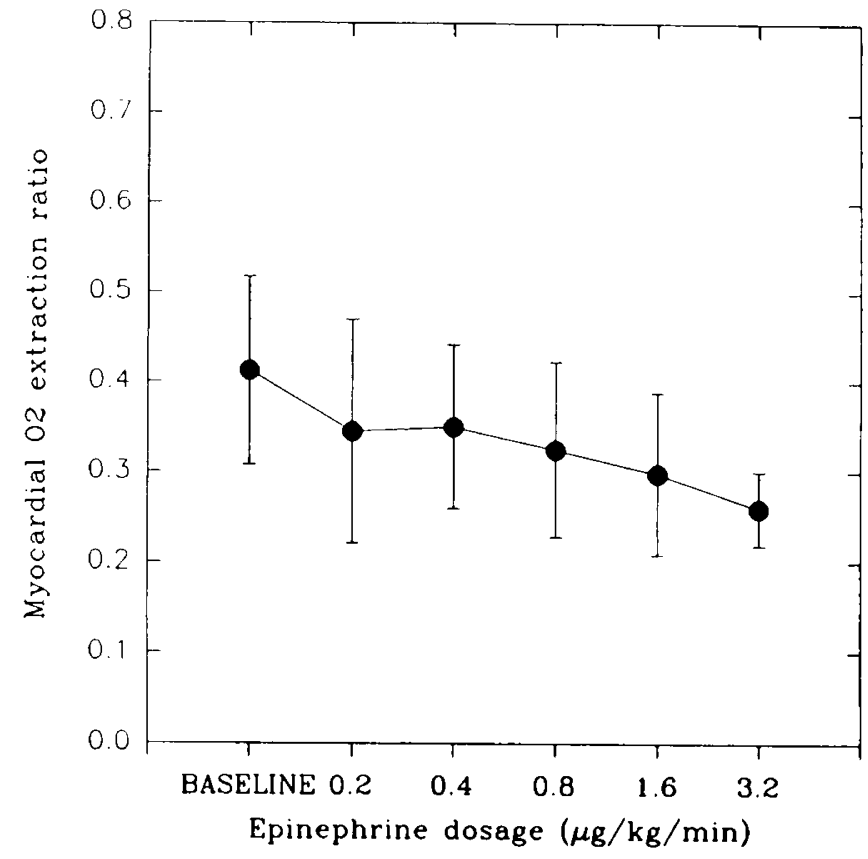

Fig. 7. Myocardial $\mathrm{O}_{2}$ extraction ratio response to epinephrine dose.

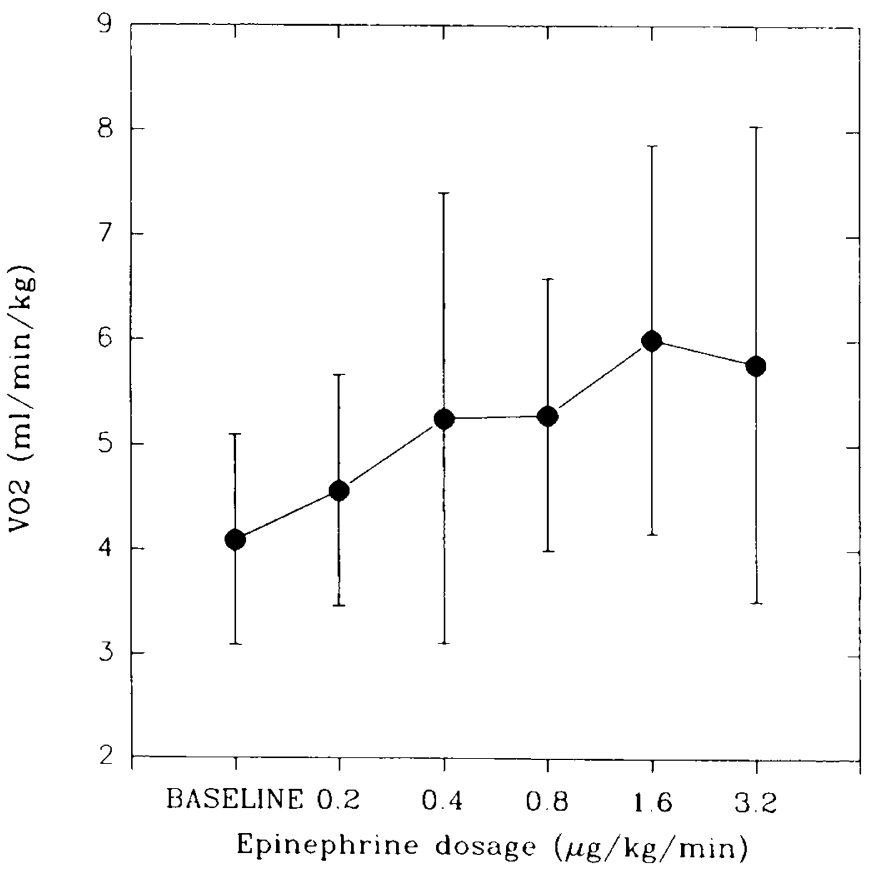

Fig. 8. Whole-body $\mathrm{O}_{2}$ consumption ( $\mathrm{I}^{\prime} \mathrm{O} 2$ ) response to increasing epinephrine dose.

highest dose that we investigated $(3.2 \mu \mathrm{g} / \mathrm{kg} / \mathrm{min})$ of $0.004 \mathrm{kPa} /$ $\mathrm{mL} / \mathrm{min} / \mathrm{kg}(0.03 \mathrm{~mm} \mathrm{Hg} / \mathrm{mL} / \mathrm{min} / \mathrm{kg})$. This difference is presumably due to the fact that our piglets were healthy and well oxygenated and had normal baseline pulmonary artery pressures, whereas those of Meadow et al. had pulmonary hypertension as a result of group B streptococcal infusions.

The effects of catecholamine infusions on myocardial $\mathrm{O}_{2}$ delivery and consumption do not appear to have been previously documented in a neonatal model. Extensive literature in mature animals (13-16) has demonstrated that direct application of adrenergic agents to coronary smooth muscle or direct infusion of the agents into coronary vessels may elicit vasoconstrictive responses. However, in the intact preparation, the increase in myocardial $\mathrm{O}_{2}$ demand caused by inotropic and chronotropic stimulation with these agents greatly overrides the direct effects 
and usually leads to coronary vasodilatation. However, differences in detail between various adrenergic agents remain. Thus, although direct infusion of epinephrine into the coronary arteries may cause vasoconstriction (5), we have demonstrated that systemic infusion of epinephrine causes a reduction in coronary vascular resistance. Coronary blood flow increases in excess of the level required to satisfy the $\mathrm{O}_{2}$ demands of the myocardium, leading to an increase in coronary sinus $\mathrm{O}_{2}$ content. This increase in $\mathrm{O}_{2}$ supply in excess of demand may be due to direct stimulation of $\beta$-receptors in the coronary circulation (4) at these doses. Gwirtz and Stone (16) have demonstrated that, in the conscious dog, norepinephrine may cause coronary vasoconstriction not evident after pentobarbital anesthesia. We would therefore caution that the results that we have demonstrated may not be appropriately extrapolated to conscious subjects. However, it is usual to sedate infants with persistent pulmonary hypertension of the newborn, and therefore the effects of epinephrine on myocardial $\mathrm{O}_{2}$ balance in our anesthetized subjects may still be relevant. The direct effects of barbiturates on the cardiovascular system consist of depression of the cardiac and vasomotor centers in the brainstem with resultant diminution in cardiac output, blood pressure, and SVR index (17). The direct myocardial depressant actions of barbiturates appear to be significant only in lethal doses (18). There is no clear evidence that barbiturates interfere with cardiovascular responses to catecholamines. The cardiovascular depressant effects of barbiturates appear to be significantly less than those of halothane, which we administered only briefly for anesthetic induction. The blood pressure in halothane-anesthetized piglets averages approximately two thirds of that demonstrated in these pentobarbital-anesthetized piglets (19). Although it may be preferable to ascertain the effects of epinephrine infusion in the absence of any anesthetic agent, it is clearly not ethically justifiable with this preparation.

The use of pancuronium probably does not affect the significance of our results, inasmuch as others have demonstrated minimal effects on myocardial $\mathrm{O}_{2}$ balance (20), and the effects would remain stable throughout the experiment. Furthermore, many infants with persistent pulmonary hypertension receive muscle relaxants. Although pancuronium may increase heart rate in older subjects and thus, presumably, myocardial $\mathrm{O}_{2}$ demands, this does not appear to be true in newborn animals (21). The baseline, postpancuronium heart rate of our animals, i.e. 212 (SD 32) was within the range described for awake piglets of the same postnatal age, which is approximately 170 to 240 (22). Also, the use of positive end-expiratory pressure during ventilation may have slightly reduced coronary blood flow (23). However, this was necessary to avoid the progressive deterioration in gas exchange that occurs in newborn piglets ventilated without positive end-expiratory pressure, and again the effects would be stable throughout the experiment. It is important to realize that in some circumstances, e.g. after asphyxia or with other causes of myocardial dysfunction, these results may not be applicable. In such a clinical situation, the myocardium may be unresponsive to the positive inotropic effects of catecholamines, and only the peripheral vascular effects may be evident.

In summary, we have demonstrated that epinephrine, when given by systemic infusion to the newborn piglet, increases cardiac output. decreases SVR and PVR in low doses, and increases both to a different degree in moderate to high doses. An investigation of the effects of even lower doses would be appropriate. Myocardial $\mathrm{O}_{2}$ consumption is increased by epinephrine, but to a lesser extent than myocardial $\mathrm{O}_{2}$ delivery. Thus, the cautious use of epinephrine for therapy of infants with pulmonary hypertension is probably warranted, as is further investigation of epinephrine effects in other newborn models and a comparison with dopamine, the most commonly used inotrope in the newborn (1).

\section{REFERENCES}

1. Perkin RM, Levin DL 1982 Shock in the pediatric patient. Part II. Therapy. J Pediatr 101:319-332

2. Fox WW, Duara S 1983 Persistent pulmonary hypertension in the neonate: diagnosis and management. J Pediatr 103:505-513

3. Meadow WL, Rudinsky BF, Strates E 1986 Selective elevation of systemic blood pressure by epinephrine during sepsis-induced pulmonary hypertension in piglets. Pediatr Res 20:872-875

4. Vasu MA, O'Keefe DD, Kapellakis GZ, Vezeridis MP, Jacobs ML, Daggett WM, Powell WJ 1978 Myocardial oxygen consumption: effects of epinephrine, isoproterenol, dopamine, norepinephrine, and dobutamine. Am J Physiol 235: $\mathrm{H} 237-\mathrm{H} 241$

5. Hardin RA. Scott JB, Haddy FJ 1961 Effect of epinephrine and norepinephrine on coronary vascular resistance in dogs. Am J Physiol 201:276-280

6. Lindner KH, Ahnefeld FW, Schuermann W, Bowdler IM 1990 Epinephrine and norepinephrine in cardiopulmonary resuscitation; effects on myocardial oxygen delivery and consumption. Chest 97:1458-1462

7. Rudolph AM, Mesel E, Levy JM 1963 Epinephrine in the treatment of cardiac failure due to shunts. Circulation 28:3-13

8. Balderman SC, Aldridge J 1986 Pharmacologic support of the myocardium following aorto-coronary bypass surgery: comparative study. J Clin Pharmacol 26:175-183

9. Steen PA, Tinker JH, Pluth JR, Barnhorst DA, Tarhan S 1978 Efficacy of dopamine, dobutamine, and epinephrine during emergence from cardiopulmonary bypass in man. Circulation 57:378-384

10. Tarnow J. Muller RK 1991 Cardiovascular effects of low-dose epinephrine infusions in relation to the extent of preoperative $\beta$-adrenoceptor blockade. Anesthesiology 74:1035-1043

11. Meadow WL, Rudinsky BF, Strates E 1986 Effects of phenylephrine on systemic and pulmonary artery pressure during sepsis induced pulmonary hypertension in piglets. Dev Pharmacol Ther 9:249-259

12. Shaddy RE, Tyndall MR, Teitel DF. Li C, Rudolph AM 1988 Regulation of cardiac output with controlled heart rate in newborn lambs. Pediatr Res 24:577-582

13. Crystal GJ, Kim S, Salem MR, Abdel-Latif M 1991 Myocardial oxygen supply/ demand relations during phenylephrine infusions in dogs. Anesth Analg 73:283-288

14. Woodman OL. Vatner SF 1987 Coronary vasoconstriction mediated by $\alpha_{1}$ and $\alpha_{2}$-adrenoceptors in conscious dogs. Am J Physiol 253:H388-H393

15. Moreland RS, Bohr DF 1984 Adrenergic control of coronary arteries. Fed Proc 43:2857-2861

16. Gwirtz PA, Stone HL 1982 Coronary blood flow changes following activation of adrenergic receptors in the conscious dog. Am J Physiol 243:H 13-H19

17. Price HL 1960 General anesthesia and circulatory homeostasis. Physiol Rev 40:187-218

18. Hardman HF, Moore IJ, Lum BKB 1959 A method for analyzing the effect of $\mathrm{pH}$ and of the ionization of drugs upon cardiac tissue with special reference to pentobarbital. J Pharmacol Exp Ther 126:136-142

19. Barrington KJ, Allen RG, Dewald J 1992 The renal vascular response of the newborn piglet to epinephrine infusions. Pediatr Res 31:58A(abstr)

20. Gunnicker M. Pohlen G. Hess W 1990 The influence of pancuronium and vecuronium combined with balanced anaesthesia on haemodynamics and myocardial oxygen balance. Acta Anaesthesiol Scand 34:327-334

21. Cameron CB, Gregory GA, Rudolph AM. Heymann MA 1986 Cardiovascular effects of d-tubocurarine and pancuronium in newborn lambs during normoxia and hypoxia. Pediatr Res 20:246-252

22. Gootman PM 1986 Cardiovascular regulation in developing swine. In: Tumbleson ME (ed) Swine in Biomedical Research. Plenum Press. New York, pp 1161-1178

23. Ben-Haim SA. Amar R, Shofty R, Merin G, Dinnar U 1989 The effect of positive end-expiratory pressure on the coronary blood flow. Cardiology 76:193-200 